\title{
FIk-1/KDR Mediates Ethanol-Stimulated Endothelial Cell Notch Signaling and Angiogenic Activity
}

\author{
David Morrow $^{\mathrm{a}}$ Ekaterina Hatch ${ }^{\mathrm{a}}$ Katie Hamm ${ }^{\mathrm{a}}$ Paul A. Cahill ${ }^{\mathrm{b}}$ \\ Eileen M. Redmond ${ }^{\mathrm{a}}$ \\ ${ }^{a}$ Department of Surgery, University of Rochester Medical Center, Rochester, N.Y., USA; b Vascular Biology and \\ Therapeutics Laboratory, School of Biotechnology, Dublin City University, Dublin, Ireland
}

\section{Key Words}

Alcohol - Angiogenesis - Vascular endothelium - Notch . Vascular endothelial growth factor receptor - Vascular remodeling

\section{Abstract \\ We previously reported that ethanol (EtOH) stimulates en- dothelial angiogenic activity mediated via a notch- and an- giopoietin-1 (Ang-1) pathway. As crosstalk exists between notch and vascular endothelial growth factor (VEGF) signal- ing, we examined whether the VEGF receptor (VEGFR) Flk-1 (fetal liver kinase 1) mediates EtOH-stimulated notch signal- ing and angiogenic activity. Methods and Results: Treat- ment of human coronary artery endothelial cells (HCAECs) with EtOH (1-50 mM, $24 \mathrm{~h}$ ) dose-dependently increased Flk- 1 expression with a maximum increase observed at $25 \mathrm{~mm}$ EtOH. Ethanol treatment activated both Flk-1 and FIt-1 (FMS- like tyrosine kinase 1) as indicated by their phosphorylation, and subsequent stimulation of Akt. EtOH activation of Flk-1 was inhibited by the VEGFR inhibitor SU5416. Gene silencing of Flk-1 using small interfering RNA inhibited the EtOH-in- duced increase in notch receptors 1 and 4 and notch target}

gene (hairy enhancer of split-related transcription factor 1) mRNA. Knockdown of Flk-1 inhibited EtOH-induced Ang-1/ Tie-2 mRNA expression and blocked EtOH-induced HCAEC network formation on Matrigel, a response that was restored by notch ligand, notch ligand delta-like ligand 4 , treatment. In vivo, moderate alcohol feeding increased vascular remodeling in mouse ischemic hindlimbs. Conclusions: These data demonstrate that EtOH activates Flk-1 and Flt-1 receptors in HCAECs and promotes angiogenic activity via an Flk-1/notch pathway. These effects of EtOH may be relevant to the influence of moderate alcohol consumption on cardiovascular health.

(c) 2014 S. Karger AG, Basel

\section{Introduction}

While the incidence of cardiovascular disease and morbidity increases with heavy alcohol (ethanol, EtOH) consumption and/or binge drinking, studies indicate that moderate consumption is protective [1-3]. The precise cell targets and signaling mechanisms mediating these effects of $\mathrm{EtOH}$ are not fully elucidated. Angiogenesis, i.e.

\section{KARGER}

E-Mail karger@karger.com www.karger.com/jvr (c) 2014 S. Karger AG, Base

$1018-1172 / 14 / 0514-0315 \$ 39.50 / 0$
Dr. Eileen M. Redmond

Department of Surgery, University of Rochester Medical Center Box SURG, 601 Elmwood Avenue

Rochester, NY 14642-8410 (USA)

E-Mail Eileen_Redmond@urmc.rochester.edu 
new blood vessel formation, is essential in both normal and pathological physiology and can be beneficial or deleterious depending on the circumstance [4]. With respect to cardiovascular disease, new vessel formation following heart attack or stroke is believed desirous as it can compensate for the resulting loss of perfusion and ischemia [4]. Therefore, stimulation of angiogenesis by $\mathrm{EtOH}$ in the setting of atherosclerosis-induced occlusion represents a potential novel mechanism that may contribute, in part, to its cardiovascular protective effects.

Emerging evidence indicates that the notch signaling pathway plays an important role in remodeling of the adult vasculature in general, and in angiogenesis in particular [5-7]. Indeed, adult vascular endothelial cells, whose migration, proliferation, differentiation and structural rearrangement are central to the angiogenic process, express notch receptors (predominately notch 1 and 4 ) though little is known to date of their regulation and function in this particular cell type. In general, upon ligand binding, the notch receptor is cleaved allowing the intracellular portion to translocate to the nucleus where it derepresses transcription and modulates the expression of notch target genes that regulate cell fate decisions. These target genes include the 'hairy enhancer of split' gene and its related transcription factors (Hrts) $[8,9]$. We have previously demonstrated that EtOH, at levels consistent with moderate consumption, stimulates endothelial angiogenic activity in vitro via a novel notch/angiopoietin-1 (Ang-1)/Tie-2-dependent pathway [5].

The vascular endothelial growth factor (VEGF) family of ligands and receptors are established regulators of angiogenesis $[10,11]$. VEGF- $A,-B,-C$ and $-D$ are ligands for receptor tyrosine kinases VEGFR1 (FMS-like tryrosine kinase 1, Flt-1) and VEGFR2 (kinase domain-containing receptor, KDR, also called fetal liver kinase 1, Flk1). VEGF-A, the major ligand for angiogenesis, binds and activates both VEGFR1/Flt-1 and VEGFR2/Flk-1. On ligand binding, VEGFRs initiate autophosphorylation and induce tyrosine kinase activity, stimulating cellular responses including the PLC $\gamma$-PKC-Raf kinase-MEKMAPK pathway (stimulating cell growth) and the PI3KAkt pathway (promoting cell survival) [12]. Both stimulatory and inhibitory effects of alcohol on the VEGF-VEGFR axis have been previously reported [13, 14]. Moreover, numerous studies in mammalian cell culture and in vivo support extensive crosstalk between notch and VEGF $[7,15,16]$. Building on these reports in the literature and our previous studies, we investigated the involvement of the VEGF pathway in EtOH-stimulated endothelial cell angiogenic activity. We report here that EtOH activates Flk-1 and Flt-1 receptors and promotes angiogenic activity via an Flk-1/notch pathway. These data add new mechanistic information as to how EtOH affects vascular endothelial cells and may be relevant to the cardiovascular protective effect of moderate alcoholic beverage consumption.

\section{Materials and Methods}

\section{Cell Culture}

Human coronary artery endothelial cells (HCAECs) were obtained from Lonza (Walkersville, Md., USA) and cultured in optimized endothelial cell medium (Clonetics ${ }^{\circledR}$, Lonza). Cells were assessed for endothelial cell phenotype by morphology and for the expression of von Willebrand factor antigen and platelet-endothelial cell adhesion molecule. HCAECs between passages 3 and 12 were used in all experiments. EtOH (200 proof, ACS/USP grade, Pharmco Products, Brookfield, Conn., USA) was diluted in media to achieve the desired concentrations (1-50 mM) before being added to HCAECs in culture for either $24 \mathrm{~h}$ (protein and mRNA expression analysis) or 5-30 min (receptor activation experiments) as indicated. Alternatively, HCAECs were treated with hrVEGF165 (30 ng/ml, R \& D Systems, Minneapolis, Minn., USA) for 5-30 min.

\section{Quantitative Real-Time RT-PCR}

Total RNA $(0.5-1 \mu \mathrm{g})$, isolated from cells using a Qiagen RNeasy kit (Valencia, Calif., USA) was reverse-transcribed using an iscript ${ }^{\mathrm{TM}} \mathrm{cDNA}$ synthesis kit from Bio-Rad (Carlsbad, Calif., USA). The gene-specific oligonucleotide sequences were designed using NCBI/Primer blast and primers that specifically spanned exon-exon junctions, utilized to eliminate genomic DNA contamination. Comparative $\mathrm{Ct}$ analysis using SYBER green-based real-time RT-PCR was performed where calibrator controls were selected using the Stratagene MX3005 machine and the SYBER green jumpstart PCR kit (Sigma, St. Louis, Mo., USA) as described by the manufacturer.

\section{Western Blot Analysis}

Proteins from cell lysates $(12-15 \mu \mathrm{g})$ were resolved on sodium dodecyl sulfate polyacrylamide gel electrophoresis (12\% resolving, $5 \%$ stacking) prior to transfer onto nitrocellulose membranes (Amersham Biosciences, Piscataway, N.J., USA). Membranes were stained with Ponceau S and probed for glyceraldehyde 3-phosphate dehydrogenase (GAPDH) to ensure equal protein loading and transfer and rinsed in wash buffer (PBS containing $0.05 \%$ Tween-20) before being probed using commercially available antibodies from Abcam (Cambridge, Mass., USA). All primary antibody dilutions were 1:500 (overnight) with corresponding 1:10,000 secondary dilutions $(2 \mathrm{~h}$ ). Following secondary antibody incubation, membranes were rinsed in wash buffer (PBS containing $0.05 \%$ Tween-20) before being stained with Clarity ${ }^{\mathrm{TM}}$ ECL Western Substrate Solution (Bio-Rad). Membranes were then analyzed for protein expression using the Chemidoc ${ }^{\mathrm{TM}} \mathrm{XRS}+$ system (Bio$\mathrm{Rad})$. Band Intensity was quantified and normalized for protein concentration $(\mathrm{GAPDH})$ using the Image $\mathrm{Lab}^{\mathrm{TM}}$ software (Bio$\mathrm{Rad})$. 
Angiogenic Activity (Network Formation on Matrigel)

Ninety-six-well tissue culture plates were coated with BD Matrigel $^{\mathrm{TM}}$ (100 $\mu \mathrm{l} /$ well, Becton-Dickinson, Franklin Lakes, N.J., USA), which was allowed to solidify at $37^{\circ} \mathrm{C}$ for $30 \mathrm{~min}$ before plating the cells. HCAECs $\left(3 \times 10^{3}\right.$ cells $)$, which had been treated with or without EtOH for $24 \mathrm{~h}$, were then plated at $125 \mu \mathrm{l} /$ well onto the surface of the Matrigel and incubated at $37 \mathrm{C}$. After $16 \mathrm{~h}$, the cells were photographed with the use of a CCD digital camera (Spot RT, Diagnostics Instruments Inc., Sterling Heights, Mich., USA) at a magnification of $\times 4$. Network formation was quantified by measuring the length of the network of connected cells in each well by drawing a line over them and measuring the length of the line in pixels with the use of SpotSoftware Version 4.6 (Diagnostic Instruments Inc.) essentially as described by us previously $[5,17]$. In parallel experiments, angiotensin- 1 and Tie- 2 mRNA and protein expression was also determined as an additional measurement of angiogenic activity.

\section{Small Interfering RNA Transfection}

For gene-silencing studies, the Gene Pulser XcellTM system (Bio-Rad) was used for transient transfection of HCAECs with gene-specific small interfering RNA (siRNA; 60-70\% transfection efficiency achieved). Briefly, $2 \times 10^{5}$ cells were transfected with $2 \mu \mathrm{g}$ of siRNA-targeting Flk-1 (Ambion, Austin, Tex., USA) or a scrambled negative control siRNA (Ambion, cat. No. 4611) in $75 \mu \mathrm{l}$ of siRNA electroporation buffer. Following transfection, cells were treated with or without EtOH for $24 \mathrm{~h}$ and/or notch ligand delta-like ligand 4 (Dll4, $2.0 \mu \mathrm{g})$.

\section{Alcohol Gavage}

Eight- to 10-week-old male C57BL6 mice were divided into 2 groups: 'control' and 'moderate EtOH'. For 1 week the moderate $\mathrm{EtOH}$ group received by oral gavage $0.8 \mathrm{~g} / \mathrm{kg}$ of 200 proof $\mathrm{EtOH}$ in a total volume of $200 \mu \mathrm{l}$ water, giving a peak blood alcohol concentration of approximately $15 \mathrm{~mm}$ [18], whereas the control group was gavaged daily with an isocaloric water/cornstarch mixture. After the 1-week equilibration period, hindlimb ischemia was achieved in all mice (as described below), and the control or alcohol feeding regimens continued up to 7 days after surgery.

\section{Hindlimb Ischemia}

Hindlimb ischemia was achieved in mice by unilateral ligation of the femoral artery [19]. The common femoral artery was ligated twice proximal to the popliteal and the caudal femoral arteries. The epigastric artery was also ligated. After confirming successful limb ischemia by checking the severe paleness of the foot, the overlying skin was closed with sutures.

\section{Monitoring of Hindlimb Blood Flow}

Before and on days 3 and 7 after femoral ligation, the ischemic (right)/normal (left) limb blood flow ratio was measured by use of a Moor Infrared Laser Doppler Imager (MOORLDI12-IR, Moor Instruments Inc., Wilmington, Del., USA). Before scanning was initiated, mice were placed on a heating plate at $37^{\circ} \mathrm{C}$ to minimize temperature variation. After laser Doppler color images had been recorded twice, the average perfusion of the ischemic and nonischemic limbs was calculated on the basis of colored histogram pixels. The data was analyzed with Moor laser Doppler image processing software V3.09. Perfusion was expressed as the ratio of flow in the ischemic/nonischemic hindlimb after background subtraction.

Flk-1 Mediates Ethanol-Stimulated Notch and Angiogenesis

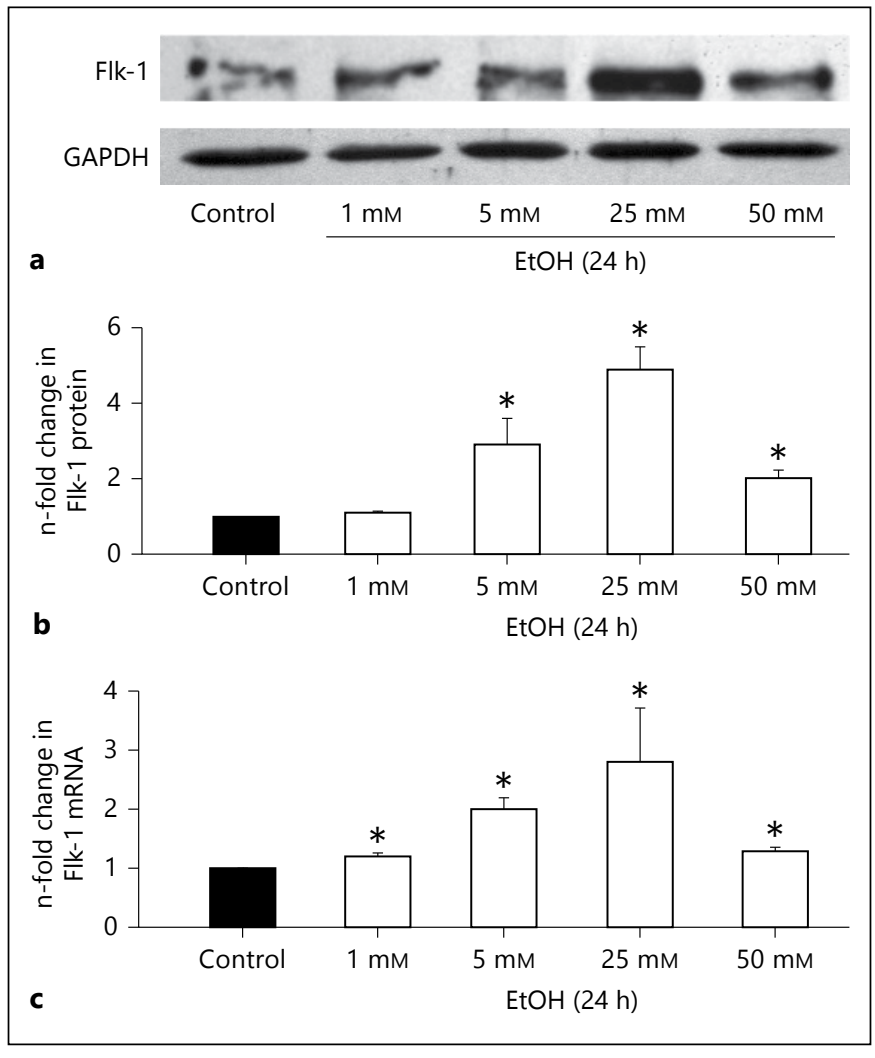

Fig. 1. EtOH stimulates Flk-1 expression in HCAECs. HCAECs were treated with or without EtOH (1-50 mM) for 24 h. ${ }^{*} \mathrm{p}<0.05$ versus control. a Representative Western blots. b Cumulative data, showing changes in Flk-1 protein expression following EtOH treatment. c Quantitative RT-PCR analysis of Flk-1 mRNA expression following EtOH treatment. Data were normalized to GAPDH and represent the mean + SEM values from 4 independent experiments.

\section{Data Analysis}

Results are expressed as means \pm SEM. Experimental points were performed in triplicate, with a minimum of 3 independent experiments. For the hindlimb ischemia study, 4-6 mice were used per experimental point. An analysis of variance test was performed on network formation data, and a Wilcoxon signed rank test was used for comparison of two groups when compared to the normalized control. A value of $\mathrm{p} \leq 0.05$ was considered significant.

\section{Results}

\section{Ethanol Increases Expression and Activates Flk-1 in HCAECs}

Exposure of HCAECs to ethanol (EtOH 1-50 mM, $24 \mathrm{~h}$ ) did not affect VEGF-A levels (data not shown), but dose-dependently increased Flk-1 (i.e. VEGFR2) expression in the moderate range up to $25 \mathrm{mM}$ while showing only a subtle increase at the higher dose of $50 \mathrm{~mm}$ (fig. 1). 
Fig. 2. EtOH activates Flt-1 and Flk-1 receptors in HCAECs. a Representative Western blot data showing phospho-Flk-1 following EtOH (25 mM), VEGF (30 ng) or combined EtOH/VEGF treatment for 0 (control), 5, 10 and 30 min. b, c Representative Western blots of phospho-Flt-1 \pm $\mathrm{EtOH}$ (b) and EtOH-induced phosphoFlk1 expression (c), in the absence or presence of the VEGFR inhibitor SU5416 (10 $\mu \mathrm{M}, 30$ min pretreatment). d Phospho-Akt following EtOH (25 mM), VEGF (30 ng) or combined EtOH/VEGF treatment for 0 (control), 5, 10 and $30 \mathrm{~min}$.

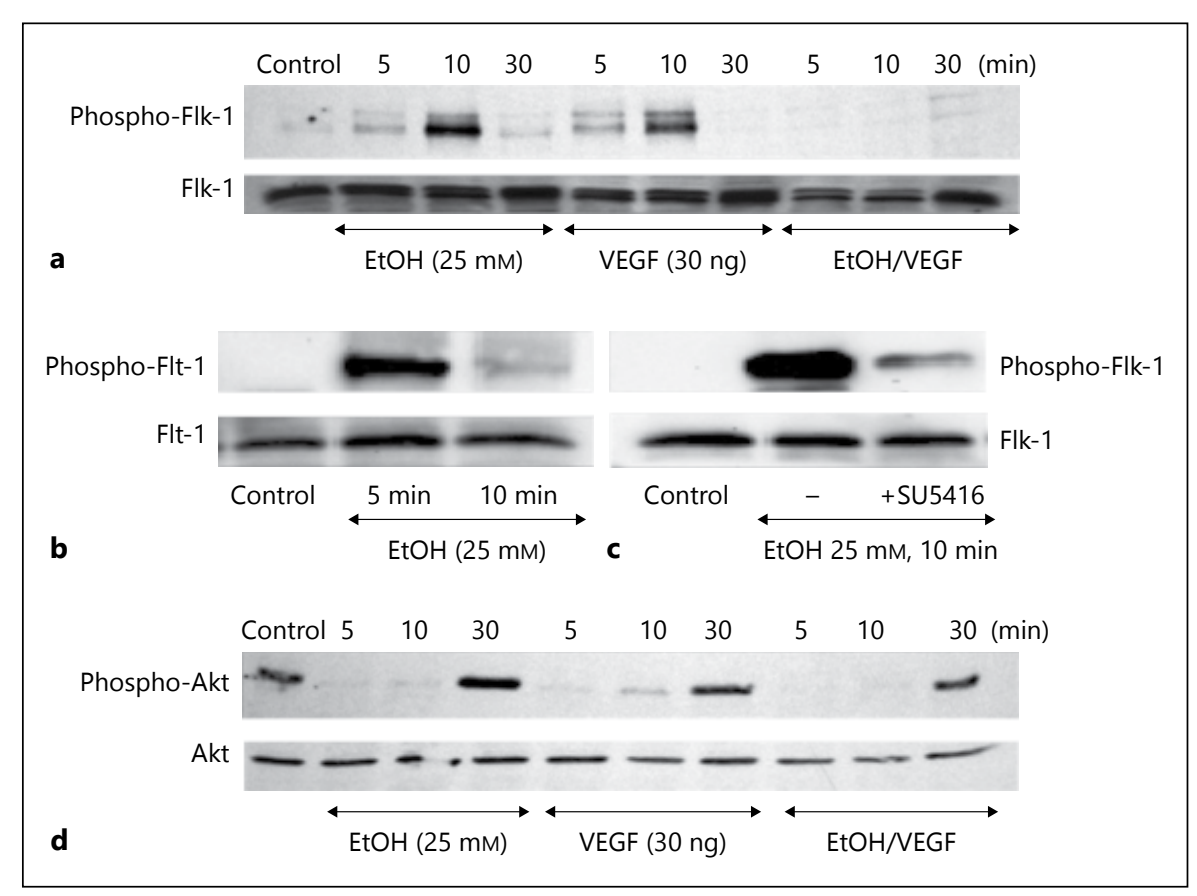

Thus, a maximum response was observed at $25 \mathrm{mM}$ EtOH with a $4.9 \pm 0.7$ and $2.8 \pm 0.9$-fold increase in Flk- 1 protein and mRNA expression, respectively. Flt-1 (VEGFR1) mRNA expression was also increased by EtOH, but to a lesser extent (data not shown). EtOH (1-50 mM, $24 \mathrm{~h}$ ) had no effect on HCAEC viability as determined by trypan blue exclusion (data not shown).

Exposure of HCAECs to VEGF $\left(\mathrm{hrVEGF}_{165}, 30 \mathrm{ng} / \mathrm{ml}\right.$, 5 and $10 \mathrm{~min}$ ) caused the expected activation of Flk-1 as evidenced by increased Flk-1 Tyr ${ }^{1054}$ and Tyr ${ }^{1059}$ phosphorylation on Western blot (fig. 2). Acute EtOH treatment ( $25 \mathrm{mM}, 5$ and $10 \mathrm{~min}$ ) activated both Flk- 1 and Flt1 receptors in these cells (fig. 2). Interestingly, combined EtOH/VEGF treatment at the same concentrations and time showed no effect on Flk-1 activation (fig. 2). The VEGF receptor inhibitor SU5416 significantly attenuated the EtOH-induced Flk-1 receptor activation (fig. 2c). In parallel cultures, EtOH treatment stimulated Akt, as indicated by increased $\mathrm{Akt}^{\mathrm{Ser} 473}$ phosphorylation, to an extent greater than the stimulation by VEGF treatment (fig. 2b). In addition, there was no increase in p-Akt, compared to control, with combined EtOH/VEGF treatment (fig. 2d).

\section{Flk-1 Knockdown Inhibits EtOH-Stimulated Notch}

Signaling in HCAECs

We previously reported that EtOH stimulates notch expression and signaling in human umbilical vein endothelial cells [5]. Gene silencing of Flk-1 in HCAECs with specific targeted siRNA duplexes was confirmed at the mRNA and protein level: $>80 \%$ decrease in Flk-1 mRNA and protein expression when compared to scrambled controls (fig. 3a, b). Flk-1 siRNA significantly decreased notch receptors 1 and 4, and notch target gene Hrt-1 mRNA in control, untreated HCAECs (fig. 3c). Moreover, Flk-1 knockdown strongly attenuated EtOH-induced notch 1 and 4 and Hrt-1 mRNA expression in these cells (fig. 3c).

\section{EtOH-Induced Angiogenic Response Is Flk-1}

\section{Dependent}

EtOH treatment $(25 \mathrm{mM}, 24 \mathrm{~h})$ significantly stimulated HCAEC angiogenic activity as indicated by increased network formation on Matrigel (fig. 4). As an in vivo correlate, we used the mouse hindlimb ischemia model. There was significantly greater perfusion in the ischemic hindlimbs of moderately EtOH-gavaged mice compared to controls, 3 and 7 days after femoral artery ligation, as determined by laser Doppler imaging (fig. 5), indicative of increased vascular remodeling which may include angiogenesis. Knockdown of Flk-1 with siRNA attenuated network formation, compared to cells treated with scrambled RNA control, and completely inhibited EtOH-stimulated HCAEC network formation (fig. 4a, b). Moreover, Flk-1 siRNA reduced Ang- 1 and Tie- 2 mRNA expression in control HCAECs by $51.0 \pm 5 \%$ and $50.0 \pm 7 \%$, respectively, and completely inhibited EtOH-induced Ang-1/ Tie-2 mRNA expression (fig. 4c). 
Fig. 3. Flk-1 mediates EtOH-stimulated notch signaling in HCAECs. HCAECs transfected with scrambled RNA (control), or with an siRNA targeted to Flk-1 were treated with or without $\mathrm{EtOH}(25 \mathrm{~mm}$, $24 \mathrm{~h}$ ) before mRNA expression for notch 1 , 4 and Hrt- 1 was determined. ${ }^{a} \mathrm{p}<0.05$ versus scrambled control, ${ }^{b} \mathrm{p}<0.05$ versus EtOH control. a Cumulative data for Flk-1 mRNA expression. b Representative Western blot data in HCAECs transfected with scrambled RNA (control) or with an siRNA targeted to Flk-1. c Quantitative RT-PCR analysis of notch 1, 4 and Hrt-1 mRNA expression following $\mathrm{EtOH}$ treatment in HCAECs transfected with scrambled RNA (control), or with an siRNA targeted to Flk1. Data were normalized to GAPDH and represent the mean + SEM values from 4 independent experiments.

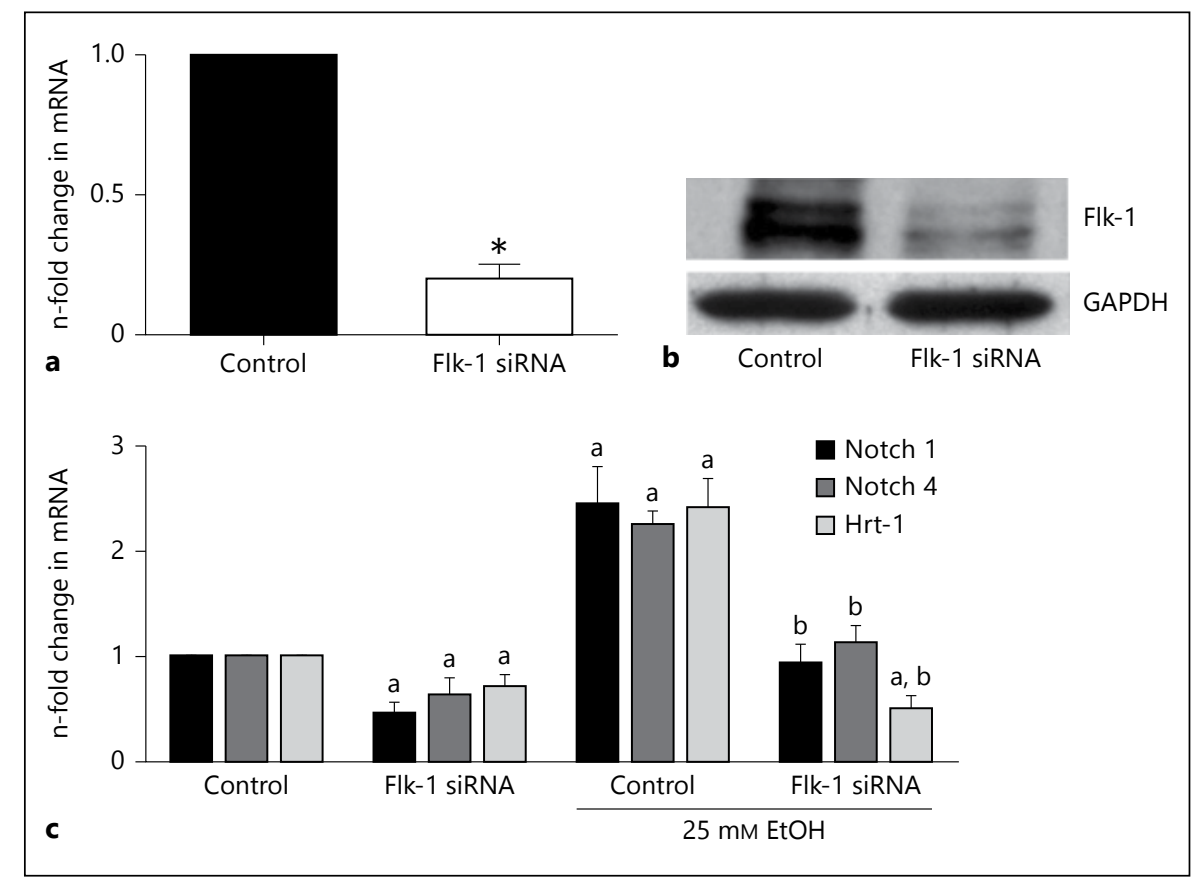

Flk-1 Mediates EtOH-Stimulated HCAEC Angiogenic Activity via a Notch-Dependent Pathway

Treatment with notch Dll4 $(2.0 \mu \mathrm{g}, 24 \mathrm{~h})$ partly recovered the Flk-1 siRNA inhibition of EtOH-induced network formation (fig. 6). In parallel cultures, treatment with notch Dll4 recovered the Flk-1 siRNA inhibition of EtOH-induced expression of notch 1 and 4 and Ang-1/ Tie-2 mRNA. These data indicate that Flk-1 mediates EtOH-stimulated HCAEC notch signaling and angiogenic activity, and that notch is downstream of VEGF.

\section{Discussion}

While heavy and/or binge drinking is deleterious to health, epidemiological studies describe moderate or 'low-risk' drinking (defined for women as no more than 3 drinks on any single day and no more than 7 drinks per week; National Institute of Alcohol Abuse and Alcoholism) as a negative risk factor for atherosclerosis and its clinical consequences, heart attack and stroke [3]. In the USA, 1 unit of alcohol (i.e. $12 \mathrm{oz}$ of beer, $5 \mathrm{oz}$ of wine or $1.5 \mathrm{oz}$ of liquor) contains $14 \mathrm{~g}$ of pure alcohol. Moderate alcohol consumption in the range of 1-3 drinks/day gives rise to blood alcohol levels of 5-25 mM [1,20]. The main type of alcohol found in alcoholic beverages is $\mathrm{EtOH}$, and a better understanding of the cellular and molecular mechanisms mediating its effects is beginning to emerge. Here we report that $\mathrm{EtOH}$, at concentrations found in moderate drinkers, increases angiogenesis in vivo and stimulates the expression and activation of the VEGFR Flk-1/KDR in cultured human coronary artery endothelial cells in vitro. Moreover, Flk-1 is critical in mediating $\mathrm{EtOH}$-stimulated notch signaling and subsequent angiogenic activity in these cells. These effects of EtOH may be relevant to the influence of moderate alcohol consumption on cardiovascular health.

Migration and proliferation of endothelial cells is critical to angiogenesis which is associated with a variety of pathologies and can be beneficial or harmful, depending on the clinical situation [4]. Thus, control of angiogenesis represents an area of considerable therapeutic potential. With regard to cardiovascular disease, the role of angiogenesis is complex and context-dependent. For example, atherosclerotic plaque angiogenesis seems to characterize the inflammatory, more vulnerable plaque, and a positive association between neovessel density and plaque rupture has been reported [21]. In contrast, coronary collateral angiogenesis in response to occlusion ischemia can compensate for loss of perfusion following myocardial infarct or stroke and in this way can protect tissues from ischemic damage $[22,23]$. Clinical observations indicate that the extent of collateralization among patients with cardiovascular disease varies considerably [23-25], with the 


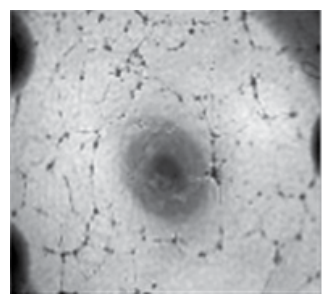

Control
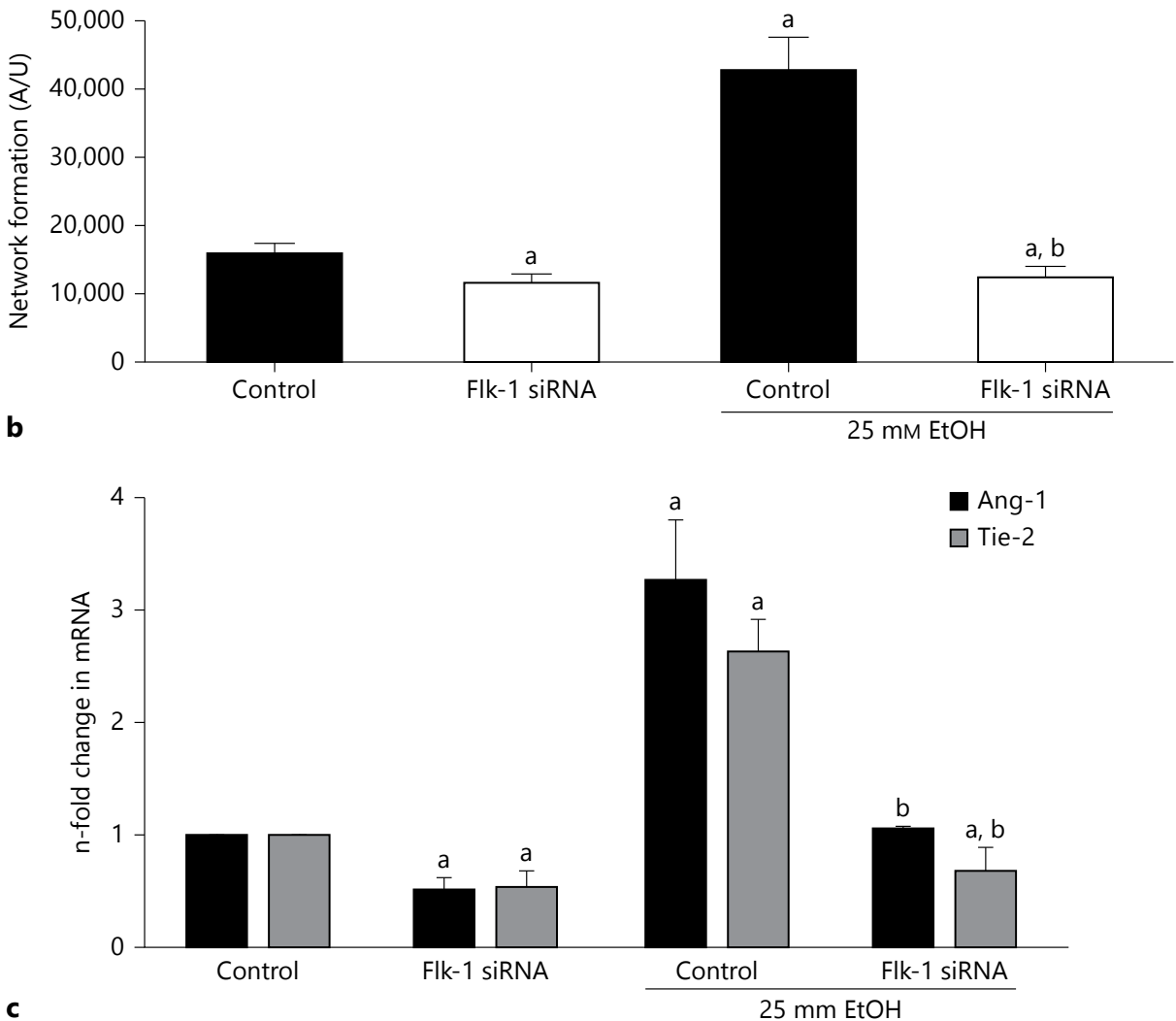

Fig. 4. Flk-1 gene knockdown inhibits $\mathrm{EtOH}$-induced angiogenic activity. ${ }^{\mathrm{a}} \mathrm{p}<0.05$ versus scrambled control, ${ }^{\mathrm{b}} \mathrm{p}>0.05$ versus EtOH control. a, b HCAECs transfected with scrambled RNA (control), or with an siRNA targeted to Flk-1 were treated with or without $\mathrm{EtOH}(25 \mathrm{mM}, 24 \mathrm{~h})$ before network formation on Matrigel was assessed (representative images and cumulative data from 3 sepa-
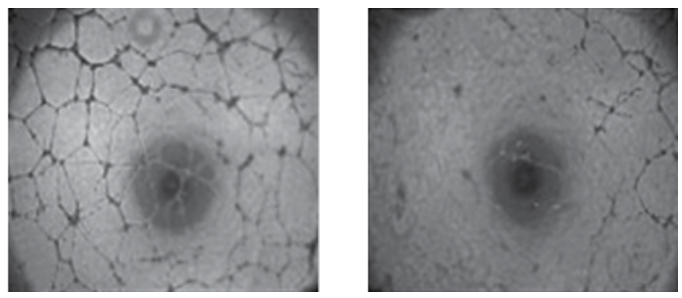

Control Flk-1 siRNA

$25 \mathrm{~mm} \mathrm{EtOH}$ rate experiments conducted in triplicate are shown). $\mathrm{A} / \mathrm{U}=\mathrm{Arbi}-$ trary units. c Ang-1 and Tie-2 mRNA levels were analyzed by quantitative RT-PCR in HCAEC transfected with scrambled RNA (control), or with an siRNA targeted to Flk-1 treated with or without EtOH ( $25 \mathrm{~mm}, 24 \mathrm{~h})$. Data were normalized to GAPDH and represent the mean + SEM values from 3 independent experiments. factors responsible for this variation unclear. An understanding of the contributing causes, which may include genetic elements or lifestyle habits such as drinking, is therefore desirable. Indeed, recent research studies support a modulatory effect of alcohol consumption on neovessel formation in the heart. Lassaletta et al. [26] re- ported that diet supplementation with moderate doses of EtOH increased arteriolar density and improved myocardial perfusion in chronically ischemic swine myocardium. Louboutin et al. [27] reported in a rat model that alcohol feeding stimulated VEGF production, increased the number of capillaries in the heart and protected the 
Fig. 5. a Representative laser Doppler flow images of a C57Bl/6 mouse before and after surgery (i.e. femoral artery ligation). $\mathrm{R}=$ Right; L = left foot. Low perfusion is depicted as blue color (colors in the online version only), whereas red color represents high perfusion. $\mathbf{b}$ Changes in perfusion after ligation shown as a ratio of right to left hindlimb (R/L ratio). Cumulative data, $\mathrm{n}=$ 3. ${ }^{*} \mathrm{p}<0.05$ versus before surgery. c Greater perfusion 3 and 7 days after femoral artery ligation in moderate $\mathrm{EtOH}-\mathrm{fed}$ animals, compared to controls (C). $\mathrm{n}=4-6$. ${ }^{*} \mathrm{p}<0.05$ versus control.

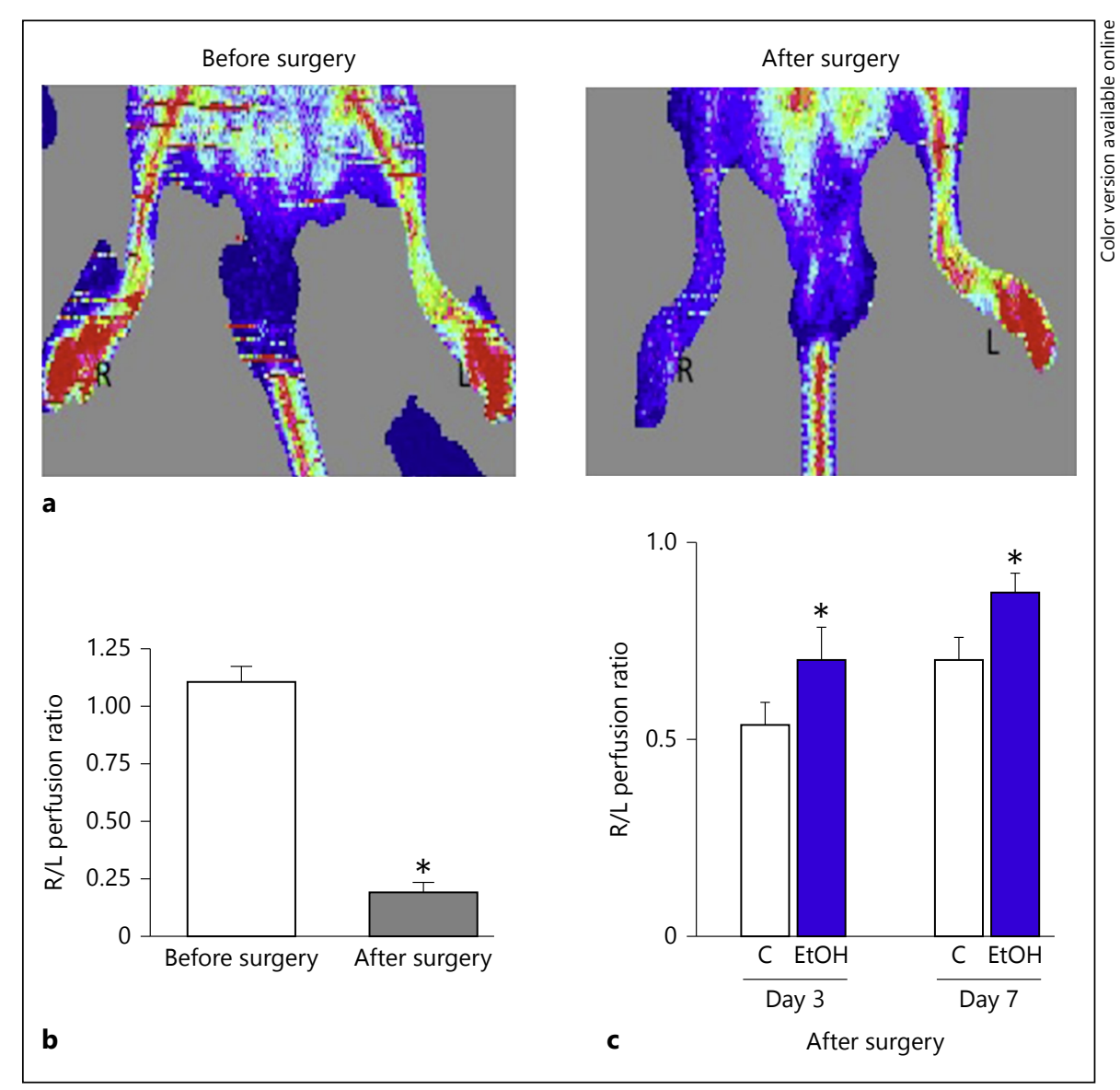

heart from myocardial ischemia/reperfusion injury. The effects of EtOH in that study were inhibited by VEGFneutralizing antibody [27]. Similarly, our data in the hindlimb ischemia mouse model suggests that EtOH feeding increases vascular remodeling in response to ischemia, which is usually a combination of arteriogenesis and angiogenesis, as indicated by significantly greater perfusion after ligation in the moderate $\mathrm{EtOH}$-fed group compared to controls (no alcohol). In apparent contrast, $\mathrm{EtOH}$ consumption reportedly diminished the protective effect of estrogen on infarct size and myocardial capillary density in ovariectomized mice [28]. Despite these contradictory reports, available evidence supports a modulatory effect of alcohol on angiogenesis in the heart.

Several other groups have also investigated the effect of EtOH on angiogenesis, not only in the context of cardiovascular disease, but also in tumorigenesis and wound healing, in a variety of in vitro and in vivo models. We previously reported that $\mathrm{EtOH}$, at levels consistent with moderate consumption, stimulated endothelial cell growth and migration, key processes in angiogenesis [5].
In that study, EtOH promoted angiogenic activity in human umbilical vein endothelial cells by stimulating a novel notch/Ang-1 pathway [5]. These in vitro data, and the new data in HCAECs presented here, are in general agreement with the in vivo studies mentioned above demonstrating a stimulatory effect of alcohol consumption on myocardial neovessel development $[26,27]$ and with several other studies reporting a stimulatory effect of EtOH on angiogenesis, some looking at tumor angiogenesis [13, 29-31]. At least one group describes an inhibitory effect of EtOH on angiogenesis in the context of wound healing $[14,32]$. These apparently contradictory findings are likely due to differing experimental doses, exposure times and/or models used. Nevertheless, our data support a stimulatory effect of ethanol on endothelial cell (both human umbilical vein endothelial cells and HCAECs) angiogenic activity as determined by a Matrigel in vitro angiogenesis assay which models the tube formation 'morphogenesis' stage of angiogenesis [33].

The VEGF family of ligands and receptors are established regulators of angiogenesis $[10,11]$ and both stimu- 


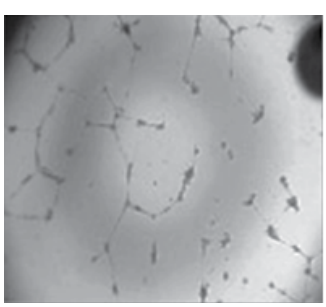

Control

a

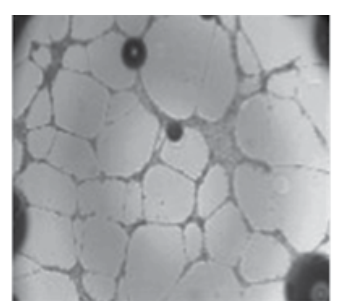

Control

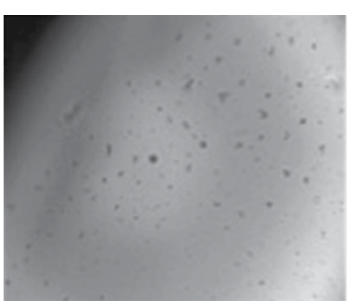

Flk-1 siRNA

$25 \mathrm{mM}$ EtOH

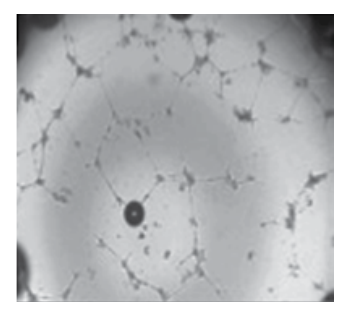

Flk-1 siRNA/DII4
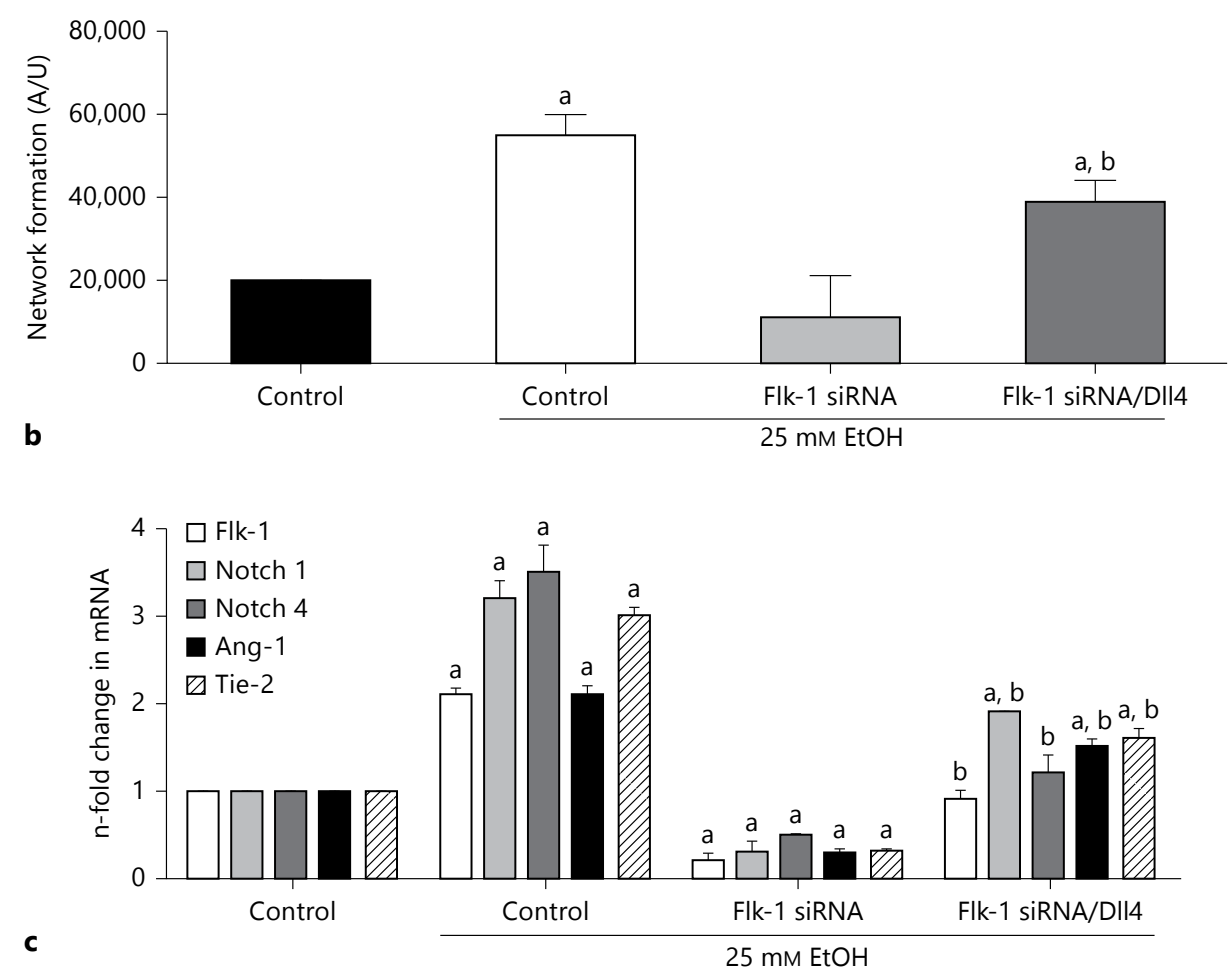

Fig. 6. Flk-1 mediates EtOH-stimulated HCAEC angiogenic activity via a notch-dependent pathway. ${ }^{a} \mathrm{p}<0.05$ versus scrambled control, ${ }^{\mathrm{b}} \mathrm{p}>0.05$ versus Flk- 1 siRNA/EtOH. a, b HCAECs transfected with scrambled RNA (control) or with an siRNA targeted to Flk-1 were treated with or without EtOH ( $25 \mathrm{mM}, 24 \mathrm{~h})$ and/or Dll4 $(2.0 \mu \mathrm{g}, 24 \mathrm{~h})$ before network formation on Matrigel was assessed (representative images and cumulative data from 3 separate ex- periments conducted in triplicate are shown). A/U = Arbitrary units. c Notch 1 and 4, Hrt-1, Ang-1 and Tie-2 mRNA levels were analyzed by quantitative RT-PCR in HCAECs transfected with scrambled RNA (control), or with an siRNA targeted to Flk-1 treated with or without EtOH $(25 \mathrm{mM}, 24 \mathrm{~h})$ and/or Dll4 $(2.0 \mu \mathrm{g}$, $24 \mathrm{~h}$ ). Data were normalized to GAPDH and represent the mean + SEM values from 3 independent experiments. latory and inhibitory effects of EtOH on VEGF have been reported [13, 27, 32]. Given that there is evidence of extensive crosstalk between notch and VEGF signaling pathways $[7,15,16,34-36]$, we investigated the possibility that stimulation of notch and subsequent angiogenesis in endothelial cells by $\mathrm{EtOH}$ is mediated via its effect on VEGF. EtOH dose-dependently increased Flk-1 expression, in the absence of any effect on VEGF-A levels, and activated Flk-1 and downstream Akt. Gene knockdown experiments illustrated the critical requirement for Flk-1 in mediating the EtOH-induced notch signaling and endothelial angiogenic response. Moreover, treatment with a notch ligand partly recovered the EtOH notch and angiogenic responses in cells in which Flk-1 was knocked down illustrating the directional hierarchy of the pathway, i.e. VEGF upstream of notch. 
While others have also demonstrated a stimulatory effect of EtOH on VEGF and on VEGF receptor expression $[13,37,38]$, few have reported whether EtOH acts to stimulate Flk-1 receptor activation like our data indicate. Precisely how EtOH activates Flk-1, an effect blocked by the VEGFR inhibitor SU5416, is not clear at present. Of note EtOH stimulates endothelial nitric oxide synthase activity resulting in increased nitric oxide [39]. Nitric oxide has previously been reported to cause Flk-1 receptor phosphorylation in cardiomyocytes [40]. Thus, EtOH activation of the Flk-1 receptor in HCAECs could be an indirect effect via nitric oxide. Moreover, we found it interesting that despite their individual stimulatory effects, a combination of both EtOH and VEGF had essentially no effect on Flk-1 receptor activation/autophosphorylation. The reasons for this unexpected result are not obvious at present. It is possible that some direct chemical interaction occurs between the two agonists that negates an agonist effect of either at the Flk-1 receptor. Alternatively, because EtOH promotes the proangiogenic action of
Ang-1 and angiopoietins have been shown to inhibit VEGF-A actions in endothelial cells [41], it is also possible that Ang-1 inhibits VEGF activation of Flk-1 when $\mathrm{EtOH}$ is present. Further investigation is warranted to fully understand this effect.

In conclusion, our findings illuminate a critical role for the VEGFR2 (Flk-1/KDR) in mediating the stimulatory effect of $\mathrm{EtOH}$ on notch signaling and subsequent angiogenic activity in HCAECs. This mechanistic information adds to our understanding of how alcohol affects vascular endothelial cells whose function is critical not only in angiogenesis, but also in vascular homeostasis and vascular pathologies such as atherosclerosis.

\section{Acknowledgements}

This study was supported in part by funds from the National Institutes of Health (RO1AA12610 and R21AA020365 to E.M.R. and R00HL095650 to D.M.) and the Science Foundation Ireland (SFI-11PI/1128 to P.A.C.).

\section{References}

$>1$ Thun MJ, Peto R, Lopez AD, Monaco JH, Henley SJ, Heath CW Jr, Doll R: Alcohol consumption and mortality among middle-aged and elderly US adults. N Engl J Med 1997;337: 1705-1714.

$>2$ Pearson TA: Alcohol and heart disease. Cir culation 1996;94:3023-3025.

$>3$ Di Castelnuovo A, Costanzo S, Bagnardi V, Donati MB, Iacoviello L, de Gaetano G: Alcohol dosing and total mortality in men and women: an updated meta-analysis of 34 prospective studies. Arch Intern Med 2006;166: 2437-2445.

4 Carmeliet P: Angiogenesis in life, disease and medicine. Nature 2005;438:932-936.

$\checkmark 5$ Morrow D, Cullen JP, Cahill PA, Redmond EM: Ethanol stimulates endothelial cell angiogenic activity via a notch- and angiopoietin-1-dependent pathway. Cardiovasc Res 2008;79:313-321.

6 Ridgway J, Zhang G, Wu Y, Stawicki S, Liang WC, Chanthery Y, Kowalski J, Watts RJ, Callahan C, Kasman I, Singh M, Chien M, Tan C, Hongo JA, de Sauvage F, Plowman G, Yan M: Inhibition of Dll4 signalling inhibits tumour growth by deregulating angiogenesis. Nature 2006;444:1083-1087.

7 Takeshita K, Satoh M, Ii M, Silver M, Limbourg FP, Mukai Y, Rikitake Y, Radtke F, Gridley T, Losordo DW, Liao JK: Critical role of endothelial notch 1 signaling in postnatal angiogenesis. Circ Res 2007;100:70-78.

$>8$ Lai EC: Keeping a good pathway down: transcriptional repression of notch pathway target genes by CSL proteins. EMBO Rep 2002;3: 840-845.

$>9$ Iso T, Kedes L, Hamamori Y: HES and HERP families: multiple effectors of the notch signaling pathway. J Cell Physiol 2003;194:237-255.

10 Breen EC: VEGF in biological control. J Cell Biochem 2007;102:1358-1367.

11 Yla-Herttuala S, Rissanen TT, Vajanto I, Hartikainen J: Vascular endothelial growth factors: biology and current status of clinical applications in cardiovascular medicine. J Am Coll Cardiol 2007;49:1015-1026.

$>12$ Ellis LM: The role of neuropilins in cancer. Mol Cancer Ther 2006;5:1099-1107.

13 Tan W, Bailey AP, Shparago M, Busby B, Covington J, Johnson JW, Young E, Gu JW: Chronic alcohol consumption stimulates VEGF expression, tumor angiogenesis and progression of melanoma in mice. Cancer Biol Ther 2007;6:1211-1217.

$>14$ Radek KA, Matthies AM, Burns AL, Heinrich SA, Kovacs EJ, Dipietro LA: Acute ethanol exposure impairs angiogenesis and the proliferative phase of wound healing. Am J Physiol Heart Circ Physiol 2005;289:H1084-H1090.

15 Liu ZJ, Shirakawa T, Li Y, Soma A, Oka M, Dotto GP, Fairman RM, Velazquez OC, Herlyn M: Regulation of notch1 and Dll4 by vascular endothelial growth factor in arterial endothelial cells: implications for modulating arteriogenesis and angiogenesis. Mol Cell Biol 2003;23:14-25.

16 Morrow D, Cullen JP, Liu W, Guha S, Sweeney C, Birney YA, Collins N, Walls D, Red- mond EM, Cahill PA: Sonic hedgehog induces notch target gene expression in vascular smooth muscle cells via VEGF-A. Arterioscler Thromb Vasc Biol 2009;29:1112-1118.

$\checkmark 17$ Morrow D, Cullen JP, Cahill PA, Redmond EM: Cyclic strain regulates the notch/CBF-1 signaling pathway in endothelial cells: role in angiogenic activity. Arterioscler Thromb Vasc Biol 2007;27:1289-1296.

18 Morrow D, Cullen JP, Liu W, Cahill PA, Redmond EM: Alcohol inhibits smooth muscle cell proliferation via regulation of the notch signaling pathway. Arterioscler Thromb Vasc Biol 2010;30:2597-2603.

19 Tirziu D, Moodie KL, Zhuang ZW, Singer K, Helisch A, Dunn JF, Li W, Singh J, Simons M: Delayed arteriogenesis in hypercholesterolemic mice. Circulation 2005;112:2501-2509.

20 Mukamal KJ, Conigrave KM, Mittleman MA, Camargo CA Jr, Stampfer MJ, Willett WC, Rimm EB: Roles of drinking pattern and type of alcohol consumed in coronary heart disease in men. N Engl J Med 2003;348:109-118.

21 Moreno PR, Purushothaman KR, Fuster V, Echeverri D, Truszczynska H, Sharma SK, Badimon JJ, O'Connor WN: Plaque neovascularization is increased in ruptured atherosclerotic lesions of human aorta: implications for plaque vulnerability. Circulation 2004; 110:2032-2038.

22 Koerselman J, van der Graaf Y, de Jaegere PP, Grobbee DE: Coronary collaterals: an important and underexposed aspect of coronary artery disease. Circulation 2003;107:2507-2511. 
23 Rubanyi GM: Mechanistic, technical, and clinical perspectives in therapeutic stimulation of coronary collateral development by angiogenic growth factors. Mol Ther 2013;21: 725-738.

24 Koerselman J, de Jaegere PP, Verhaar MC, Grobbee DE, van der Graaf Y: Coronary collateral circulation: the effects of smoking and alcohol. Atherosclerosis 2007;191:191-198.

25 Hansen JF: Coronary collateral circulation: clinical significance and influence on survival in patients with coronary artery occlusion. Am Heart J 1989;117:290-295.

26 Lassaletta AD, Elmadhun NY, Liu Y, Feng J, Burgess TA, Karlson NW, Laham RJ, Sellke FW: Ethanol promotes arteriogenesis and restores perfusion to chronically ischemic myocardium. Circulation 2013;128:S136-S143.

-27 Louboutin JP, Marusich E, Gao E, Agrawal L, Koch WJ, Strayer DS: Ethanol protects from injury due to ischemia and reperfusion by increasing vascularity via vascular endothelial growth factor. Alcohol 2012;46:441-454.

28 Mackie AR, Krishnamurthy P, Verma SK, Thorne T, Ramirez V, Qin G, Abramova T, Hamada H, Losordo DW, Kishore R: Alcohol consumption negates estrogen-mediated myocardial repair in ovariectomized mice by inhibiting endothelial progenitor cell mobilization and function. J Biol Chem 2013;288 18022-18034.
29 Jones MK, Sarfeh IJ, Tarnawski AS: Induction of in vitro angiogenesis in the endothelial-derived cell line, EA HY926, by ethanol is mediated through PKC and MAPK. Biochem Biophys Res Commun 1998;249:118-123.

30 Gu JW, Elam J, Sartin A, Li W, Roach R, Adair $\mathrm{TH}$ : Moderate levels of ethanol induce expression of vascular endothelial growth factor and stimulate angiogenesis. Am J Physiol Regul Integr Comp Physiol 2001;281:R365R372.

-31 Wang S, Xu M, Li F, Wang X, Bower KA, Frank JA, Lu Y, Chen G, Zhang Z, Ke Z, Shi $\mathrm{X}$, Luo J: Ethanol promotes mammary tumor growth and angiogenesis: the involvement of chemoattractant factor MCP-1. Breast Cancer Res Treat 2012;133:1037-1048.

32 Radek KA, Kovacs EJ, Gallo RL, DiPietro LA: Acute ethanol exposure disrupts VEGF receptor cell signaling in endothelial cells. Am J Physiol Heart Circ Physiol 2008;295:H174H184.

33 Goodwin AM: In vitro assays of angiogenesis for assessment of angiogenic and anti-angiogenic agents. Microvasc Res 2007;74:172183.

34 Lobov IB, Renard RA, Papadopoulos N, Gale NW, Thurston G, Yancopoulos GD, Wiegand SJ: Delta-like ligand 4 (Dll4) is induced by VEGF as a negative regulator of angiogenic sprouting. Proc Natl Acad Sci USA 2007;104: 3219-3224.

>35 Siekmann AF, Covassin L, Lawson ND: Modulation of VEGF signalling output by the notch pathway. Bioessays 2008;30:303-313.
36 Li JL, Harris AL: Crosstalk of VEGF and notch pathways in tumour angiogenesis: therapeutic implications. Front Biosci (Landmark Ed) 2009;14:3094-3110.

-37 Das SK, Mukherjee S, Vasudevan DM: Effects of long term ethanol consumption mediated oxidative stress on neovessel generation in liver. Toxicol Mech Methods 2012;22:375382

38 Neves DR, Tomada IM, Assuncao MM Marques FA, Almeida HM, Andrade JP: Effects of chronic red wine consumption on the expression of vascular endothelial growth factor, angiopoietin 1, angiopoietin 2, and its receptors in rat erectile tissue. J Food Sci 2010; 75:H79-H86

-39 Hendrickson RJ, Cahill PA, Sitzmann JV, Redmond EM: Ethanol enhances basal and flow-stimulated nitric oxide synthase activity in vitro by activating an inhibitory guanine nucleotide binding protein. J Pharmacol Exp Ther 1999;289:1293-1300.

40 Kuwabara M, Kakinuma Y, Ando M, Katare RG, Yamasaki F, Doi Y, Sato T: Nitric oxide stimulates vascular endothelial growth factor production in cardiomyocytes involved in angiogenesis. J Physiol Sci 2006;56:95-101.

41 Gavard J, Patel V, Gutkind JS: Angiopoietin-1 prevents VEGF-induced endothelial permeability by sequestering SRC through MDIA. Dev Cell 2008;14:25-36. 